\title{
Synthesis of CoPt Nanorods in Ionic Liquids
}

\author{
Yong Wang and Hong Yang* \\ Department of Chemical Engineering, University of Rochester, Rochester, NY 14627 \\ E-mail: hongyang@che.rochester.edu
}

\section{Synthesis of 1-Butyl-3-methylimidazolium bis(trifluoromethylsulfonyl)imide ionic liquid, [BMIM][Tf $\left.{ }_{2} \mathrm{~N}\right]$ :}

[BMIM][CI]. Chlorobutane (60 $\mathrm{mL}$ or 0.57 mole) and 1-methylimidazole ( $40 \mathrm{~mL}$ or 0.50 mole) were added to a $250 \mathrm{~mL}$ round-bottomed flask equipped with a reflux condenser and reacted for 24-72 $\mathrm{h}$ at $70{ }^{\circ} \mathrm{C}$ with stirring till the formation of a two-phase mixture. The top layer, which contained mostly the unreacted precursors, was decanted and ethyl acetate was used to wash the product for three times. The unreacted chemicals and the remaining ethyl acetate were removed by stirring at $70{ }^{\circ} \mathrm{C}$ under dynamic vacuum for $24 \mathrm{~h}$. The density of the product was about $1.08 \mathrm{~g} / \mathrm{mL} .{ }^{1} \mathrm{H}-\mathrm{NMR}(90 \mathrm{MHz}$, Chloroform-d) $\delta: 10.74(1 \mathrm{H}, \mathrm{m}, \mathrm{NC} \underline{H N}), 7.55\left(1 \mathrm{H}, \mathrm{m}, \mathrm{CH}_{3} \mathrm{NCHC} \underline{H N}\right), 7.40\left(1 \mathrm{H}, \mathrm{m}, \mathrm{CH}_{3} \mathrm{NC} \underline{H C H N}\right)$, $4.26\left(2 \mathrm{H}, \mathrm{NC}_{2}\left(\mathrm{CH}_{2}\right)_{2} \mathrm{CH}_{3}\right), 4.11\left(3 \mathrm{H}, \mathrm{s}, \mathrm{NC}_{3}\right), 1.82\left(2 \mathrm{H}, \mathrm{m}, \mathrm{NCH}_{2} \underline{\mathrm{C}}_{2} \mathrm{CH}_{2} \mathrm{CH}_{3}\right), 1.30(2 \mathrm{H}, \mathrm{m}$, $\left.\mathrm{N}\left(\mathrm{CH}_{2}\right)_{2} \mathrm{C}_{2} \mathrm{CH}_{3}\right), 0.90\left(3 \mathrm{H}, \mathrm{m}, \mathrm{N}\left(\mathrm{CH}_{2}\right)_{3} \mathrm{C}_{3}\right)$.

[BMIM][Tf ${ }_{2} \mathrm{~N}$ ]. [BMIM][Cl] (55 $\mathrm{g}$ or $0.32 \mathrm{~mole}$ ) was added into a $250 \mathrm{~mL}$ flask, followed by the addition of lithium bistrifluoromethanesulfonimidate $\left(\operatorname{Li}\left(\mathrm{Tf}_{2} \mathrm{~N}\right), 100 \mathrm{~g}\right.$ or 0.35 mole) and water $(20 \mathrm{~mL})$. The mixture was heated to $40^{\circ} \mathrm{C}$ and kept stirring till the formation of two phases. The bottom phase was $[\mathrm{BMIM}]\left[\mathrm{Tf}_{2} \mathrm{~N}\right]$ and top phase was the aqueous solution of lithium chloride $(\mathrm{LiCl})$. The top phase was decanted and the bottom phase was washed repeatedly with water until $\mathrm{Cl}^{-}$was completely removed. The $\mathrm{Cl}^{-}$concentration was checked qualitatively by the formation of $\mathrm{AgCl}$ after adding of silver nitrate $\left(\mathrm{AgNO}_{3}\right)$ into the decanted water. The resulting ionic liquid was heated at $100{ }^{\circ} \mathrm{C}$ under vacuum for $12 \mathrm{~h}$. The density of the final product was about $1.4 \mathrm{~g} / \mathrm{mL} .{ }^{1} \mathrm{H}-\mathrm{NMR}\left(90 \mathrm{MHz}, \mathrm{CHCl}_{3}, d\right) \delta$ : $8.80(1 \mathrm{H}, \mathrm{m}, \mathrm{NC} \underline{\mathrm{HN}}), 7.29\left(2 \mathrm{H}, \mathrm{m}, \mathrm{CH}_{3} \mathrm{NC} \underline{\mathrm{HCHN}}\right), 4.2\left(2 \mathrm{H}, \mathrm{m}, \mathrm{NC}_{2}\left(\mathrm{CH}_{2}\right)_{2} \mathrm{CH}_{3}\right), 3.96\left(3 \mathrm{H}, \mathrm{s}, \mathrm{NC}_{3}\right)$, $1.80\left(2 \mathrm{H}, \mathrm{m}, \mathrm{NCH}_{2} \mathrm{C}_{2} \mathrm{CH}_{2} \mathrm{CH}_{3}\right), 1.34\left(2 \mathrm{H}, \mathrm{m}, \mathrm{N}\left(\mathrm{CH}_{2}\right)_{2} \mathrm{C}_{2} \mathrm{CH}_{3}\right), 0.93\left(3 \mathrm{H}, \mathrm{N}\left(\mathrm{CH}_{2}\right)_{3} \underline{\mathrm{C}}_{3}\right)$. The water content in $[\mathrm{BMIM}]\left[\mathrm{Tf}_{2} \mathrm{~N}\right]$ was about $0.03 \%$, determined by Karl Fisher coulommetry method. The quantitative analysis of chlorine contents in $[\mathrm{BMIM}]\left[\mathrm{Tf}_{2} \mathrm{~N}\right]$ was performed using potentiometric titration with silver nitrate and no chloride was detectable $(<0.3 \%$ by weight $)$. 


\section{Synthesis of CoPt nanorods}

In a typical synthesis of Co-Pt nanorods, freshly dried [BMIM] $\left[\mathrm{Tf}_{2} \mathrm{~N}\right](3 \mathrm{~mL})$ was mixed with cetyltrimethylammonium bromide (CTAB, Aldrich, $137 \mathrm{mg}$ or $\sim 0.375 \mathrm{mmol}$ ) in a flask. This mixture was then heated with a heating mantle under the protection of argon. A magnetic stir bar coated with glass was used during the synthesis. CTAB dissolved in the ionic liquid at $40{ }^{\circ} \mathrm{C}$ and became a colorless transparent solution. Designed amounts of platinum acetylacetonate $\left(\mathrm{Pt}(\mathrm{acac})_{2}\right.$, Aldrich) and cobalt acetylacetonate $\left(\mathrm{Co}(\mathrm{acac})_{3}\right.$, Aldrich) were mixed with $1 \mathrm{~mL}$ of freshly dried $[\mathrm{BMIM}]\left[\mathrm{Tf}_{2} \mathrm{~N}\right]$ and injected into the flask at $350{ }^{\circ} \mathrm{C}$. The following two reactant ratios were used for making the nanorods: $\operatorname{Pt}(\mathrm{acac})_{2}(7 \mathrm{mg}$ or $\sim 0.018 \mathrm{mmol})$ with $\mathrm{Co}(\mathrm{acac})_{3}(20 \mathrm{mg}$ or $\sim 0.054 \mathrm{mmol})$ and $\mathrm{Pt}(\mathrm{acac})_{2}(50 \mathrm{mg}$ or $\sim 0.125 \mathrm{mmol})$ with $\mathrm{Co}(\mathrm{acac})_{3}(135 \mathrm{mg}$ or $\sim 0.375 \mathrm{mmol})$. The reaction temperature dropped to $\sim 325^{\circ} \mathrm{C}$ and recovered to $350{ }^{\circ} \mathrm{C}$ in $\sim 5 \mathrm{~min}$. The reaction was kept at this temperature for additional $1 \mathrm{~h}$ before it was terminated. The as-made product was centrifuged out from the black mixture at 12,000 RPM, followed by two washing cycles using acetone and another one using ethanol. The materials could be temporarily dispersed in acetone after ultrasonication and the TEM specimen were prepared from this dispersion.

\section{Synthesis of CoPt nanoparticles}

Freshly dried [BMIM] $\left[\mathrm{Tf}_{2} \mathrm{~N}\right](3 \mathrm{~mL})$ was mixed with CTAB $(137 \mathrm{mg}$ or $\sim 0.375 \mathrm{mmol})$ in a flask. This mixture was heated with a thermal mantle under the protection of argon. . A magnetic stir bar coated with glass was used during the synthesis. CTAB dissolved in $[\mathrm{BMIM}]\left[\mathrm{Tf}_{2} \mathrm{~N}\right]$ at $40{ }^{\circ} \mathrm{C}$, resulting in a colorless transparent solution. Designed amounts of $\mathrm{Pt}(\mathrm{acac})_{2}$ and $\mathrm{Co}(\mathrm{acac})_{3}$ were dispersed in 1 $\mathrm{mL}$ of $[\mathrm{BMIM}]\left[\mathrm{Tf}_{2} \mathrm{~N}\right]$ and injected into the flask at $350{ }^{\circ} \mathrm{C}$. The following two reactant ratios were used for making the nanoparticles: $\mathrm{Pt}(\mathrm{acac})_{2}(147 \mathrm{mg}$ or $\sim 0.375 \mathrm{mmol})$ with $\mathrm{Co}(\mathrm{acac})_{3}(44 \mathrm{mg}$ or $\sim 0.125$ $\mathrm{mmol})$, and $\operatorname{Pt}(\mathrm{acac})_{2}(50 \mathrm{mg}$ or $\sim 0.125 \mathrm{mmol})$ with $\mathrm{Co}(\mathrm{acac})_{3}(44 \mathrm{mg}$ or $\sim 0.125 \mathrm{mmol})$. The reaction temperature dropped to $\sim 325^{\circ} \mathrm{C}$ and recovered to $350{ }^{\circ} \mathrm{C}$ in $\sim 5 \mathrm{~min}$. The reaction was kept at this temperature for additional $1 \mathrm{~h}$ before it was terminated. The as-made product was centrifuged out from the black mixture at 12,000 RPM, followed by two washing cycles using acetone and another one using ethanol. The materials could be temporarily dispersed in acetone after ultrasonication and the TEM specimen were prepared from this dispersion.

\section{Synthesis of CoPt hyper-branched nanorods}

Freshly dried [BMIM][Tf $2 \mathrm{~N}](3 \mathrm{~mL})$ was mixed with CTAB $(137 \mathrm{mg}$ or $\sim 0.375 \mathrm{mmol})$ in a flask. This mixture was then heated with a thermal mantle under the protection of argon. A magnetic bar coated with glass was used to ensure the adequate stirring during the synthesis. CTAB dissolved in 
$[\mathrm{BMIM}]\left[\mathrm{Tf}_{2} \mathrm{~N}\right]$ at $40^{\circ} \mathrm{C}$, resulting in a colorless transparent solution. $\mathrm{Pt}(\mathrm{acac})_{2}(5.5 \mathrm{mg}$ or $\sim 0.014 \mathrm{mmol})$ and $\mathrm{Co}(\mathrm{acac})_{3}(15 \mathrm{mg}$ or $\sim 0.042 \mathrm{mmol})$ were dispersed in $1 \mathrm{~mL}$ freshly dried IL and injected into the flask at $350{ }^{\circ} \mathrm{C}$. The temperature of the reaction mixture dropped to about $325^{\circ} \mathrm{C}$ and recovered to 350 ${ }^{\circ} \mathrm{C}$ in $5 \mathrm{~min}$. The reaction was kept at this temperature for additional $1 \mathrm{~h}$ before it was terminated. The as-made product was centrifuged out from the black mixture at 12,000 RPM, followed by two washing cycles using acetone and another one using ethanol. The materials could be temporarily dispersed in acetone after ultrasonication and the TEM specimen were prepared from this dispersion.

\section{Synthesis of CoPt nanoparticle and nanorods using $\mathrm{N}$,N-dimethylhexadecylamine (DMHA) as surfactant}

DMHA (Fluke, $126 \mu \mathrm{L}$ or $\sim 0.375 \mathrm{mmol}$ ) instead of CTAB was used in the reaction at the $\operatorname{Pt}(\mathrm{acac})_{2}: \operatorname{Co}(\mathrm{acac})_{3}: \mathrm{CTAB}$ molar ratios of $3.3: 3.3: 10$ and $3.3: 10: 10$, respectively. All other reaction conditions were the same as those mentioned above.

\section{Synthesis of CoPt nanoparticles using trioctylamine (TOA) as solvent}

TOA (Aldrich) was used to substitute ILs in the reaction at the $\operatorname{Pt}(\mathrm{acac})_{2}: \mathrm{Co}(\mathrm{acac})_{3}: \mathrm{CTAB}$ molar ratio of 3.3:10:10. All other reaction conditions were the same as those mentioned above, except the reaction temperature was kept at $\sim 340^{\circ} \mathrm{C}$ (TOA evaporated rapidly at $\sim 350^{\circ} \mathrm{C}$ ).

\section{Characterization}

Transmission electron microscope (TEM) images were recorded on a JEOL JEM 2000EX microscope at an accelerating voltage of $200 \mathrm{kV}$. A field-emission scanning electron microscope (FESEM; Model LEO 982) was used to study the surface of materials. Energy-dispersive X-ray (EDX) analysis was obtained with an EDAX detector installed on the same FE-SEM. EDX analysis of individual CoPt nanoparticle or nanorod was also done using an ultrahigh vacuum scanning transmission electron microscope (UHV-STEM) with an Oxford windowless Si (Li) detector equipped with a $4 \pi$ pulse processor. This detector enables elemental identification down to boron, on areas as

small as $1 \mathrm{~nm}^{2}$ and with typically $\sim 140 \mathrm{eV}$ resolution. Powder X-ray diffraction (PXRD) spectra were recorded on a Philips MPD diffractometer with a $\mathrm{Cu} \mathrm{K} \mathrm{X}_{\alpha} \mathrm{X}$-ray source $(\lambda=1.5405 \AA)$. 


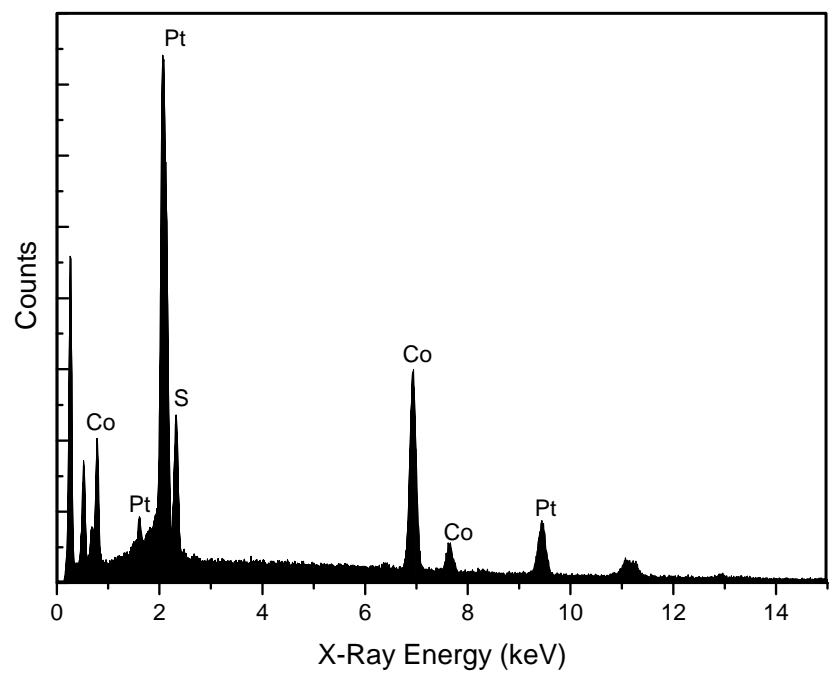

Figure S1. EDX spectrum of the bundles of nanorods obtained at the $\mathrm{Pt}(\mathrm{acac})_{2}: \mathrm{Co}(\mathrm{acac})_{3}: \mathrm{CTAB}$ molar ratio of 0.5:1.5:10. The nanorods were shown in Figure 1.

Table S1. EDX elemental analysis of the bundles of CoPt nanorods.

\begin{tabular}{llllll}
\hline & Co & $\mathrm{Pt}$ & $\mathrm{S}$ & $\mathrm{F}$ & $\mathrm{Co} / \mathrm{Pt}$ \\
Position 1 & 53.1 & 39.3 & 7.32 & 0.26 & $57: 43$ \\
Position 2 & 51.2 & 33.4 & 15.4 & 0 & $61: 39$ \\
Position 3 & 49.1 & 31.2 & 19.8 & 0 & $61: 39$ \\
Position 4 & 48.4 & 29.2 & 22.3 & 0 & $62: 38$ \\
Position 5 & 48.1 & 27.9 & 23.35 & 0.68 & $63: 37$ \\
Average & $\mathbf{5 0 . 0}$ & $\mathbf{3 2 . 2}$ & $\mathbf{1 7 . 6}$ & $\mathbf{0 . 1 9}$ & $\mathbf{6 1 : 3 9}$ \\
\hline
\end{tabular}


Table S2. EDX elemental analysis of the CoPt nanoparticles shown in Figure $2 \mathrm{~b}$.

\begin{tabular}{llllll}
\hline & Co & $\mathrm{Pt}$ & $\mathrm{S}$ & $\mathrm{F}$ & $\mathrm{Co} / \mathrm{Pt}$ \\
Position 1 & 26.7 & 49.4 & 19.2 & 4.56 & $35: 65$ \\
Position 2 & 27.1 & 51.4 & 16.1 & 5.34 & $34: 66$ \\
Position 3 & 26.8 & 52.5 & 15.7 & 5.08 & $34: 66$ \\
Position 4 & 26.3 & 47.3 & 19.4 & 7.03 & $36: 64$ \\
Position 5 & 24.4 & 44.6 & 19.6 & 11.4 & $35: 65$ \\
Average & $\mathbf{2 6 . 3}$ & $\mathbf{4 9 . 1}$ & $\mathbf{1 8 . 0}$ & $\mathbf{6 . 6 9}$ & $\mathbf{3 5 : 6 5}$ \\
\hline
\end{tabular}

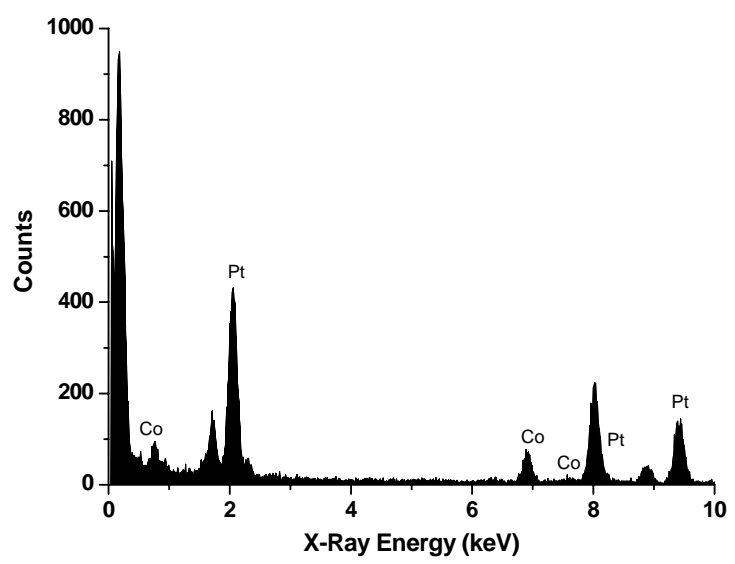

Figure S2. EDX spectrum on an individual particle formed at the $\operatorname{Pt}(\operatorname{acac})_{2}: \mathrm{Co}(\mathrm{acac})_{3}: \mathrm{CTAB}$ molar ratio of 3.3:3.3:10 using the UHV-STEM. The composition of the selected particles was found as $\mathrm{Co}_{37} \mathrm{Pt}_{63}$. 
Table S3. EDX elemental analysis of bundles of CoPt nanorods in Figure 2c.

\begin{tabular}{llllll}
\hline & Co & Pt & S & F & Co/Pt \\
Position 1 & 40.4 & 19.9 & 28.8 & 10.9 & $67: 33$ \\
Position 2 & 43.6 & 20.6 & 26.7 & 9.08 & $68: 32$ \\
Position 3 & 43.7 & 20.7 & 26.9 & 8.67 & $68: 32$ \\
Position 4 & 43.6 & 20.4 & 27.3 & 8.75 & $68: 32$ \\
Position 5 & 39.7 & 19.1 & 29.1 & 12.1 & $68: 32$ \\
Average & $\mathbf{4 2 . 2}$ & $\mathbf{2 0 . 1}$ & $\mathbf{2 7 . 8}$ & $\mathbf{9 . 9 0}$ & $\mathbf{6 8 : 3 2}$ \\
\hline
\end{tabular}

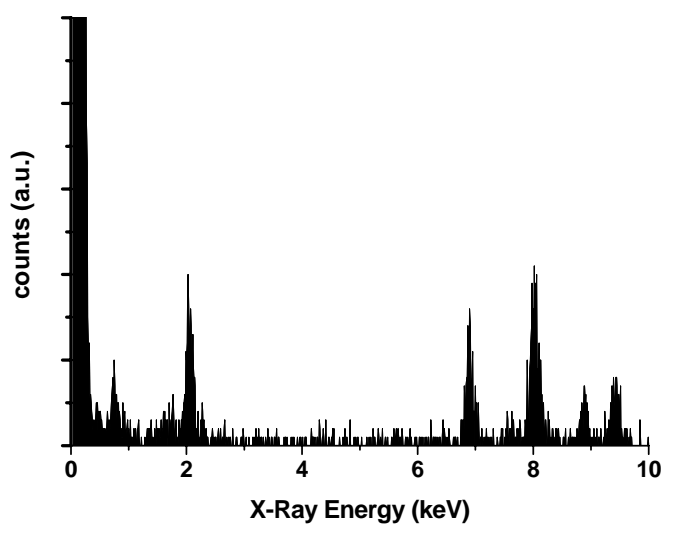

Figure S3. EDX spectrum on a single rod shown in Figure 2c using the UHV-STEM. The Co/Pt atomic ratio in the nanorod was found to be $\mathrm{Co}_{75} \mathrm{Pt}_{25}$. 


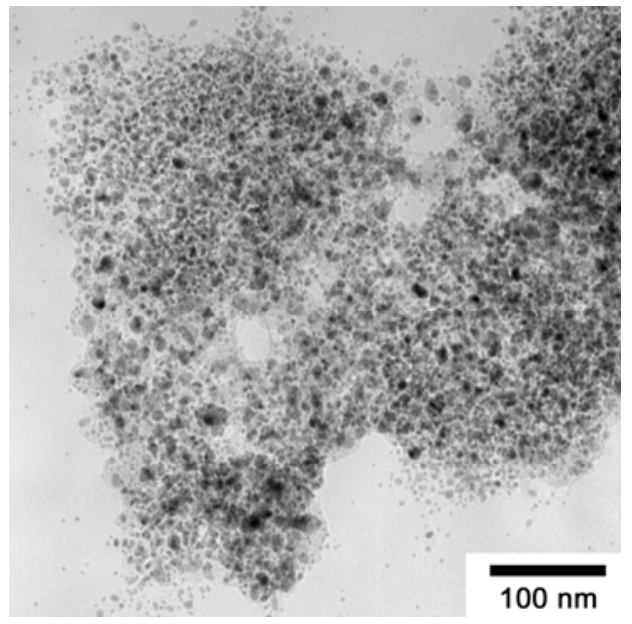

Figure S4. Representative TEM image of the nanoparticles obtained at the $\mathrm{Pt}(\mathrm{acac})_{2}: \mathrm{Co}(\mathrm{acac})_{3}: \mathrm{CTAB}$ molar ratio of $3.3: 10: 10$ in $4 \mathrm{~mL}$ of TOA at $340{ }^{\circ} \mathrm{C}$. 

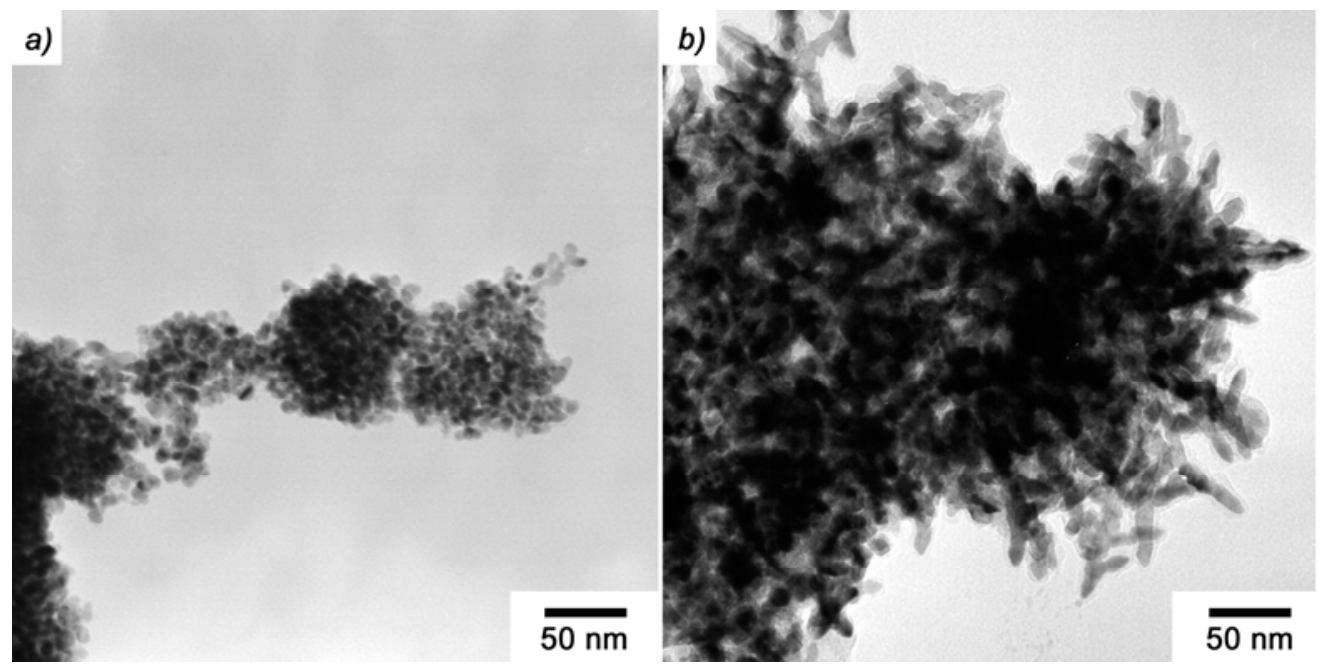

Figure S5. TEM images of CoPt (a) nanoparticles and (b) nanorods obtained using DMHA as the surfactant. The $\mathrm{Pt}(\mathrm{acac})_{2}: \mathrm{Co}(\mathrm{acac})_{3}: \mathrm{DMHA}$ molar ratios were (a) 3.3:3.3:10 and (b) 3.3:10:10, respectively. 